\title{
Pengendalian Kualitas Produksi dengan Metode Six Sigma pada Industri UMKM Terhadap Jumlah Permintaan Kerudung
}

\author{
Sofiyanurriyanti ${ }^{1 *}$ dan Mahasin Maulana Ahmad ${ }^{2}$ \\ ${ }^{1}$ Program Studi Teknik Industri, Sekolah Tinggi Teknik Qomaruddin Gresik \\ ${ }^{2}$ Program Studi Teknik Elektro, Sekolah Tinggi Teknik Qomaruddin Gresik \\ *e-mail corresponding author : sofiyanurriyanti20@gmail.com
}

\begin{abstract}
ABSTRAK
Pengendalian kualitas merupakan teknik yang digunakan untuk mengendalikan, mengelola proses manufaktur maupun jasa dengan menganalisis, mengelola dan memperbaiki produk dengan menggunakan metode statistik. Penelitian ini bertujuan untuk menganalisis persediaan bahan baku dengan menggunakan metode peramalan, serta menentukan jumlah permintaan kebutuhan, mengetahui penyebab terjadinya cacat pada produksi dengan memberikan usulan perbaikan pada proses pembuatan kerudung. Langkah prosedur penelitian ini dilakukan beberapa tahapan antara lain moving average, exponential smootbing, define, measure, analyze, improve, control. Hasil penelitian yang didapatkan jenis defect produk kerudung antara lain jahitan kurang rapi, kain yang digunakan kusut, terdapat lubang pada kain kerudung, tinta pada warna tidak sesuai saat cetak, lingkungan yang kurang kondusif sehingga pekerja kurang fokus saat bekerja. Untuk hasil dari perhitungan dari six sigma didapatkan nilai Defect per Million Opportunity diperoleh nilai sebesar 1916,33 dan nilai sigma sebesar 4,391 .
\end{abstract}

Kata kunci : metode six sigma; SIPOC; peramalan; fishbone; 5W-1H

\begin{abstract}
Quality control is a technique used to control, manage manufacturing processes and services by analyzing, managing and improving products using statistical methods. This study aims to determine the cause of defects in production by providing suggestions for improvement in the process of making a veil. The steps of this research procedure are carried out several stages including moving average, exponential smoothing, define, measure, analyze, improve, control. The results of this research show that the defect of hood products is not neat stitching, the fabric used is wrinkled, there are boles in the veil fabric, ink on the color is not suitable when printing, the environment is less conducive so workers are less focused when working. For the results of calculations from six sigma obtained Defect per Million Opportunity value obtained a value of 1916.33 and a sigma value of 4.391 .
\end{abstract}

Keywords: six sigma method; SIPOC; forecastin;, fishbone; $5 \mathrm{~W}-1 \mathrm{H}$

Cara Mengutip : Sofiyanurriyanti, S., Ahmad, M. M. (2020). Pengendalian Kualitas Produksi dengan Metode Six Sigma pada Industri UMKM Terhadap Jumlah Permintaan Kerudung. Reka Buana : Jurnal Ilmiah Teknike Sipil dan Teknik Kimia, 5(1), 63-73. http://dx.doi.org/10.33366/rekabuana.v5i1.1654 


\section{PENDAHULUAN}

Pertumbuhan Industri di Indonesia saat ini semakin ketat. Persaingan pasar antar usaha juga menjadikan salah satu tantangan yang tidak dapat dihindari dengan berbagai produk khas yang diunggulkan. Salah satunya adalah home industry. Berbagai permasalahan untuk membutuhkan komitmen dari pemilik atau pengusaha home industry antara lain belum adanya standar kualitas terhadap produk yang akan diunggulkan, pemilihan bahan baku, penggunaan bahan baku yang diinginkan, proses produksi yang dilakukan, penentuan ukuran produk yang berdasarkan dari pemilik usaha [1]. Agar dapat bersaing dengan industri lain perusahaan juga harus mampu mempertahankan dan meningkatkan kelangsungan usaha di masa mendatang baik dari input, process, output. Baik atau tidaknya prospek penjualan suatu produk pada dasarnya juga tidak hanya pada kemampuan atau pengunaan peramalan yang tepat namun juga pentingnya dalam menentukan perencanaan produksi. Perencanaan yang efektif baik untuk jangka panjang maupun jangka pendek tergantung dari peramalan permintaan produk usaha [2]. Peramalan juga dapat memberikan perbandingan metode yang memiliki nilai kesalahan terkecil dengan memenuhi kebutuhan pelanggan berdasarkan hasil ramalan yang dapat diperhitungkan dari stock persediaan [3].

Menurut Vincent Gaspersz [4] Peramalan merupakan salah satu aktivitas suatu bisnis yang memperkirakan penjualan dan penggunaan produk yang dapat dibuat dalam kuantitas yang tepat sesuai. Ada tiga langkah peramalan menurut Sofyan Assauri [5], antara lain menganalisa data yang lalu, menentukan data yang dipergunakan

dengan memberikan hasil ramalan yang tidak jauh berbeda, memproyeksikan data masa lalu dengan mempertimbangkan perubahan kebijakan pemerintah, perkembangan masyarakat, perkembangan teknologi serta penemuan baru.

Tujuan penelitian ini adalah menganalisis jumlah persediaan barang dengan menggunakan metode peramalan, menentukan jumlah permintaan kebutuhan konsumen, mengetahui penyebab terjadinya cacat pada produksi pembuatan kerudung dan memberikan usulan perbaikan dan mengurangi jumlah waste yang dihasilkan pada jumlah cacat kerudung.

Salah satu unggulan dari usaha mikro kecil menengah yang terdapat di Desa Sukowati ini diantaranya pengrajin songkok, pengrajin terbang (banjari, hadrah dan rebana), usaha terasi, usaha kerupuk dan usaha kerudung hijab. Salah satu produk unggulannya di Desa Sukowati Bungah Gresik adalah kerudung. Meskipun produk ini sangat diminati namun kualitas produk yang dihasilkan sangatlah kurang peminat. Sehingga banyaknya jenis cacat produk yang dihasilkan setiap satu item produk kerudung selama proses produksi berlangsung. Hal ini dapat menyebabkan kerugian bagi home industry. Dalam proses pembuatan kerudung ini membutuhkan berbagai peralatan yang sederhana, jumlah tenaga kerja yang kurang, ruangan yang tidak kondusif, sehingga usha bome industry ini perlu dilakukan perbaikan dalam sistem pengendalian kualitas produk.

Pengendalian kualitas adalah suatu
kegiatan yang dilakukan untuk
meminimalisasi produk cacat yang mungkin
terjadi baik dalam menjaga kualitas produk
maupun jasa sesuai dengan kebutuhan pasar


[6]. Pengendalian kualitas menurut Ilham N. M. [7] kualitas adalah suatu produk dalam keadaan fisik, fungsi dan sifat yang dapat memenuhi kebutuhan konsumen, selera dengan memuaskan sesuai nilai uang yang telah dikerluarkan. Salah satu alat yang digunakan untuk pengendalian kualitas yaitu dengan mengetahui tingkat cacat atau langkah perbaikan dengan metode six sigma.

Menurut Achmad Muhaemin [1] tahap-tahap implementasi pada six sigma terdiri lima langkah yaitu define, measuare, analyze, improve, control.

Penelitian ini dimulai dengan analisis perencanaan terhadap home industry kemudian dilakukan dengan peramalan permintaan yang diperoleh dari data historis dari home industry. Hampir semua bome industry atau perusahaan juga membutuhkan hasil ramalan penjualan karena peramalan sangat dibutuhkan untuk jangka pendek saja namun untuk jangka panjang. Tentunya setiap usaha memiliki pangsa pasar sendiri.

Salah satu cara untuk memenangkan persaingan adalah dengan menarik konsumen dengan menghasilkan produk yang sesuai dengan keinginan dan kebutuhan konsumen sehari hari [6]. Suatu produk jika dikatakan berkualitas apabila produk tersebut memenuhi kriteria yang telah ditetapkan dan diinginkan oleh keinginan dari konsumen [8]. Hal lain yang dapat dilakukan adalah dengan menawarkan atau mempromosikan produk yang berkualitas dan mampu untuk mempertahankan serta dapat meningkatkan kualitas dari produk yang dihasilkan [9], Kualitas produk yang baik dapat ditandai dari jumlah permintaan yang tidak hanya datang dari wilayah sekitar, selain itu untuk memenuhi kebutuhan konsumen usaha yang tepat dalam memperkirakan jumlah Permintaan dimasa yang akan datang dengan menunjukkan perencanaan yang tidak efektif selama tiga tahun terakhir ini sehingga keputusan yang diambil dari home industry dalam menganalisis perkiraan pada penjualan kerudung, memiliki banyak kelemahan yaitu sering terjadinya kesalahan dalam peramalan yang menyebabkan kuantitas produk yang dihasilkan tidak sesuai dengan penjualan dan permintaan. Sehingga ketika hasil jumlah produksi kerudung dibuat banyak maka stock yang ada di gudang juga akan menumpuk, sedangkan jika produk kerudung disimpan terlalu lama di gudang maka kerusakan semakin banyak. Oleh karena itu untuk meminimalisir segala dampak yang terjadi penelitian ini dilakukan perlu untuk mengadakan perbaikan strategi yang tepat guna untuk memilih atau menerapkan metode peramalan yang tepat pada perencanaan produksi jumlah kerudung dimasa yang akan mendatang [9].

\section{METODE PENELITIAN}

\section{Lokasi Penelitian}

Penelitian ini dilaksanakan di home industry yang bertempat di Desa Sukowati Bungah Gresik.

\section{Teknik Pengumpulan Data}

Teknik pengumpulan data dalam penelitian ini menggunakan 3 tahap antara lain :

a. Observasi

Observasi dilakukan dengan cara pengamatan secara langsung ke bome industry kerudung. Pengamatan ini dilakukan dengan mengetahui jumlah penjualan kerudung selama 3 tahun yakni 2016, 2017 dan 2018. Data 
aktivitas kegiatan ini dilakukan proses produksi pembuatan kerudung.

b. Wawancara

Wawancara yang dilakukan ini dengan Tanya jawab secara langsung dengan mengajukan pertanyaan ke pemilik bome industry

c. Studi Pustaka

Studi pustaka dilakukan dengan berbagai literature mengenai peramalan, pengendalian kualitas, six sigma, DMAIC.

\section{Analisis Data}

Analisis data dilakukan dengan menggunakan metode peramalan yaitu Moving Average, Exponential Smoothing, Weighted Moving Average, siklus DMAIC (Define, Measure, Analyze, Improve, Control), Faktor penyebab produk cacat, jumlah pengrajin kerudung, kriteria defect atribut kerudung, dan data harga bahan baku pembuatan kerudung, dan data proses produksi kerudung, menghitung analisa kapabilitas proses yang ditetapkan menggunakan satuan DPMO (Defect Per Million Opportunity), membuat peta kontrol, menentukkan CTQ (Critical To Quality) atau karateristik kualitas, pembuatan diagram SIPOC, dan 5W-1H. Berdasarkan tujuan dalam penelitian ini ada beberapa analisis

\section{HASIL DAN PEMBAHASAN}

\section{Pengumpulan Data}

Sebelum pengolahan data dilakukan dilakukan pengumpulan data yang berasal dari usaha kecil mikro kecil menengah yang merupakan pemilik dari Ibu Sultiawati yang bertinggal di Desa Sukowati Bungah Gresik. Data penjualan dapat ditunjukkan pada Tabel 1 dibawah ini: yang digunakan sebagai berikut: [10] moving average merupakan time series metode peramalan yang bersifat kuantitatif dalam menggunakan waktu sebagai dasar peramalan. Metode ini memerlukan data historis dalam jangka waktu tertentu untuk satu periode kedepan dari $\mathrm{t}$ (periode ratarata). Semakin besar nilai $t$ makan peramalan yang dihasilkan akan semakin menjauhi pola data [11].

1) Rata-rata bergerak $\mathrm{n}$ periode $=$

$$
\sum \frac{(\text { Permintaan dalam periode terdahulu })}{n}
$$

2) Metode Eksponential Smoothing

Metode peramalan yang mudah efisiensi nilai ramalan pada periode $\mathrm{t}+1$ yang merupakan nilai aktual dalam periode $\mathrm{t}$ dengan penyesuaian nilai ramalan yang terjadi pada periode $\mathrm{t}$.

$$
\mathrm{Ft}=\mathrm{Ft}-1+(\mathrm{At}-1-\mathrm{Ft}-1) \alpha
$$

3) Mengukur nilai error (kesalahan) yang digunakan Mean Absolute Deviation (MAD) dan Mean Square Error (MSE), Mean Absolute Persentage Error (MAPE).

$$
\begin{aligned}
& \text { MAD }=\frac{\sum \mid \text { Aktual }- \text { Peramalan } \mid}{n} \\
& \text { MSE }=\frac{\sum \mid \text { Aktual }- \text { Peramalan }\left.\right|^{2}}{n} \\
& \text { MAPE }=\frac{\sum_{i}^{n} 1100 \mid \text { Aktual } i \mid \text { Aktual } i}{n}
\end{aligned}
$$


Data penjualan didapatkan dari data penjualan kerudung dari 3 tahun terakhir yaitu tahun 2018 dengan total 7825 kodi, tahun 2017 total 7800 kodi, dan tahun 2016 sebesar 7850 kodi.

\section{Pengolahan Data}

\section{Tahapan Forecasting}

Dari data penjualan kerudung dapat dilihat terjadinya fluktasi penjualan secara acak selama 3 tahun secara random. Oleh karena itu untuk menentukan peramalan penjualan periode mendatang maka dengan menggunakan metode peramalan yang bersifat kuantitatif time series. Pengolahan data ini menggunakan software POM for windows pada tahun 2016, 2017, dan 2018.

a. Moving average

\begin{tabular}{|l|r|r|r|r|r|r||}
\hline \\
\hline
\end{tabular}

Gambar 2. Data Input Running Moving Average Penjualan Kerudung selama 3 periode

\begin{tabular}{|l|}
\hline Penjualan Kerudung Tahun 2016, 2017, 2018 Summary \\
\hline Measure \\
\hline
\end{tabular}

Gambar 3. Standart Error pada moving average

Berdasarkan metode moving average 4 bulanan untuk tingkat kesalahan yang paling terkecil berada di 4 bulanan dengan nilai error MAD sebesar 17,97, MSE 546,88 dan MAPE sebesar 0,03.

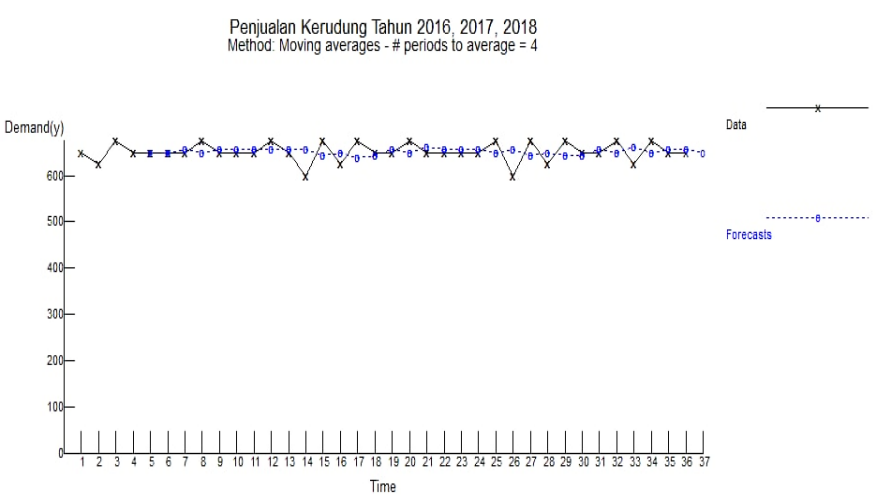

Gambar 4. Grafik Penjualan kerudung selama tiga tahun

Menunjukkan bahwa tingkat naik turunnya penjualan kerudung di bome industry pada perhitungan moving average

\section{a. Eksponential Smothing}

Perhitungan dengan menggunakan peramalan eksponential dengan nilai alfa $0.1, \quad 0.5, \quad 0.9$ untuk mengetahui perhitungan jumlah peramalan 


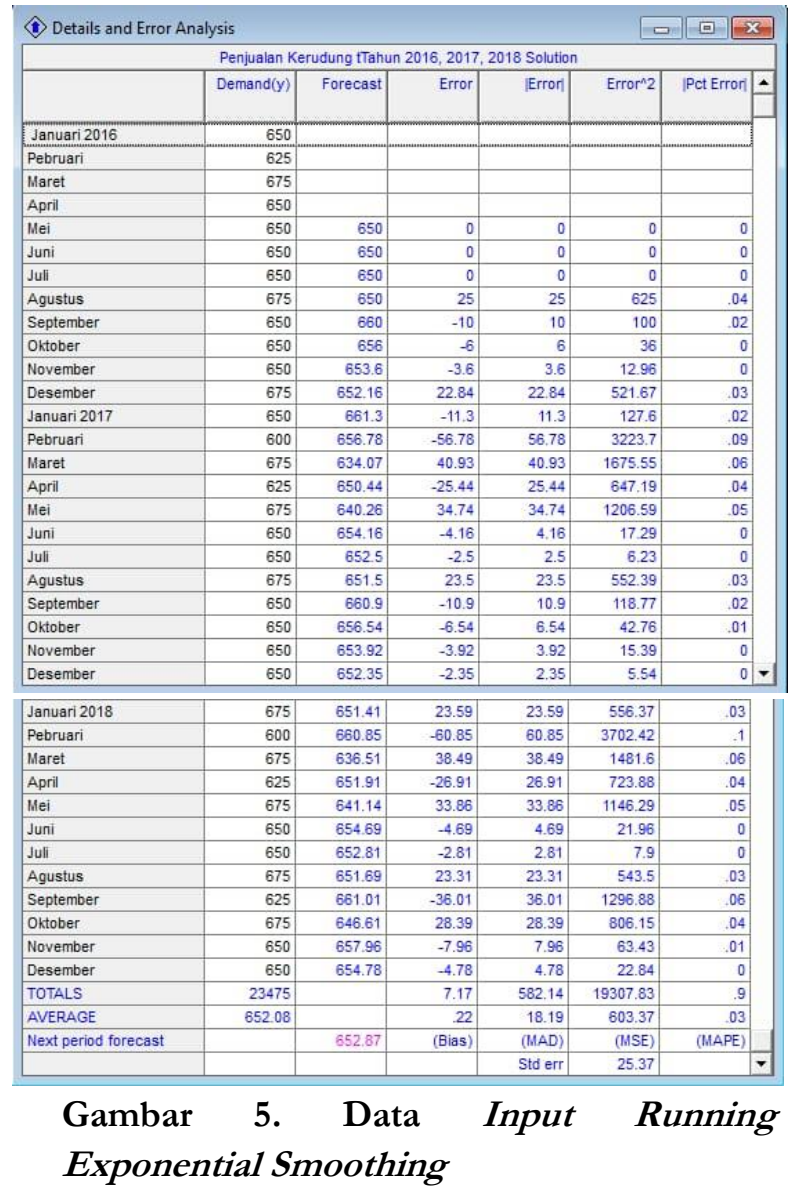

Berdasarkan hasil perhitungan menggunakan metode exponential smoothing didapatkan tingkat kesalahan yang paling terkecil yang terdapat pada nilai MAD sebesar 17,97, MSE 546,88 dan MAPE sebesar 0,03 .

ain Forecasting Results
\begin{tabular}{|l|r|}
\hline Penjualan Kerudung tTahun 2016, 2017, 2018 Summary \\
\hline Measure & Value \\
\hline & \\
\hline Error Measures & .22 \\
\hline Bias (Mean Error) & 18.19 \\
\hline MAD (Mean Absolute Deviation) & 603.37 \\
\hline MSE (Mean Squared Error) & 25.37 \\
\hline Standard Error (denom=n-2=30) & .03 \\
\hline MAPE (Mean Absolute Percent Error) & \\
\hline Forecast & 652.87 \\
\hline next period & \\
\hline
\end{tabular}

Gambar 6. Standart Error pada Exponential Smoothing

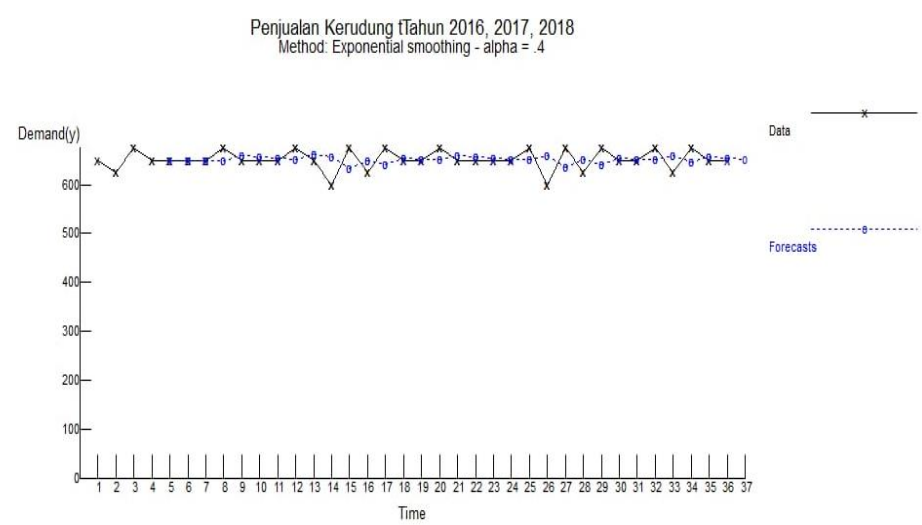

Gambar 7. Grafik Exponential Smoothing Penjualan untuk 4 bulanan Selama 3 periode

Menunjukkan bahwa tingkat naik turunnya penjualan kerudung di home industry pada perhitungan exponential smoothing.

\section{Tahapan Six Sigma (DMAIC)}

Setelah hasil peramalan diamati maka tahap selanjutnya dilakukan pada home industry kerudung ini yaitu menggunakan alat pengendalian kualitas. Tahap penyelesaian ini menggunakan metode six sigma.

\section{Tahap Define}

Pada tahap ini akan dilakukan identifikasi masalah yang diuraikan dengan menentukan critical to quality (CTQ). Pada kiteria bome industry ini ditentukan dalam CTQ

\section{Tahap Measure (tahap pengukuran)}

Pada tahap ini yang dilakukan dengan pengumpulan data dengan mengukur proses yang dilakukan perbaikan seperti pembuatan peta kendali UCL dan LCL, control chart, diagram pareto, histogram, serta perhitungan DPMO pada level sigma. 


\section{Histogram Jenis Produk Cacat}

Data Defect pada Home Industry Kerudung

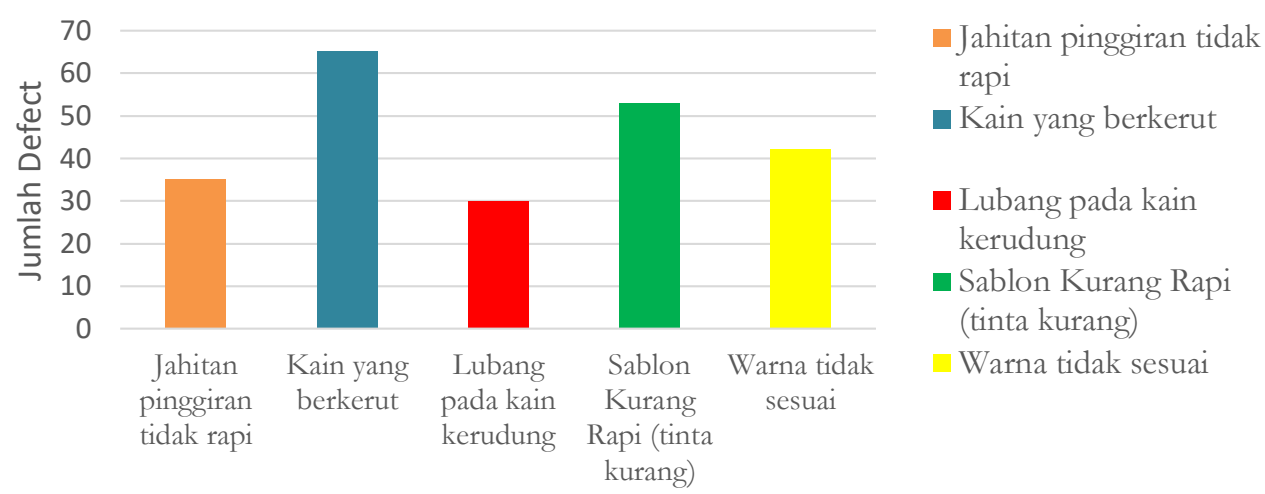

Gambar 8. CTQ Pada Home Industry Kerudung

Gambar 8 merupakan hasil wawancara dengan pemilik home industry bahwa terdapat cacatatan sederhana yang dilakukan jumlah defect yang diproduksi selama 3 tahun. Dari gambar diatas dapat dilihat jenis kerusakan yang paling sering terjadi adalah pada kain berkerut sebesar 65 unit.

\section{Membuat peta kendali (control chart)}

Pembuatan peta kendali bertujuan (UCL) dan batas control bawah (LCL). untuk melihat apakah data yang digunakan dalam melakukan perhitungan six sigma Adapaun langkah untuk membuat peta dapat dilihat dengan batas atas control atas

\section{Menghitung prosentase kerusakan (CL) Central Unit}

$P=\frac{\text { jumlah produk cacat }}{\text { jumlah produksi }}=\frac{23.475}{225}=104,33$

\section{Menghitung batas kendali atas (UCL) Upper Control Chart}

$\begin{aligned} \text { Batas Kendali Atas }(U C L)=P+3 \sqrt{\frac{p \cdot(1-p)}{n}} & =104,333+3 \times 10,214=134.97 \\ & =104,333-3 \times 10,214=73,68\end{aligned}$

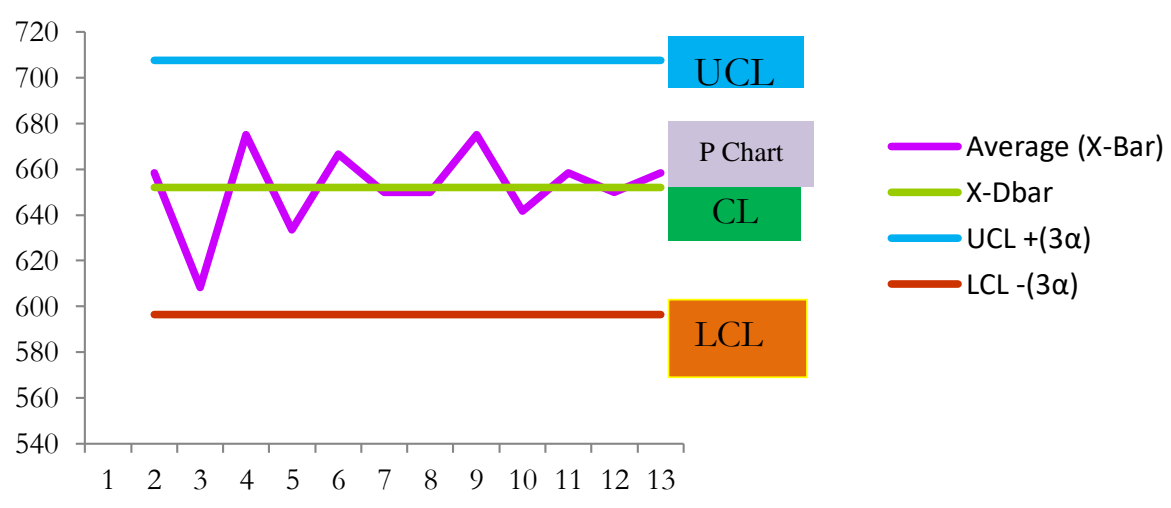

Gambar 9. Diagram $P$ chart 
Dari gambar diagram $\mathrm{P}$ chart diatas menunjukkan pengendalian dari kerusakan yang stabil dan tidak ada yang melebihi dari batas kendali atas maupun batas kendali bawah.

\section{Tahap pengukuran tingkat six sigma dengan Defect Per Million Opportunities} (DPMO)

Untuk mengukur tingkat six sigma dari hasil produksi pembuatan kerudung di bome industry dapat dilakukan dengan langkah sebagai berikut:

a) Defect Per Unit (DPU)

$$
\begin{aligned}
\text { DPU } & =\frac{\text { jumlah cacat produksi }}{\text { total produksi } x \text { jumlah CTQ }} \\
& =\frac{225}{23475}=0.0095
\end{aligned}
$$

b) Menghitung DPU

Nilai proporsi cacat yang didapat dari jumlah cacat total keseluruhan dibagi sampel

$\mathrm{DPU}=\frac{\mathrm{D}}{U}=\frac{225}{23475}=0.009585$

c) Total Opportunity (TOP)

Banyaknya kesempatan terjadinya jenis cacat yang termasuk karateristik bagi kualitas (CTQ) dari seluruh produk yang dihasilkan.

$$
\begin{aligned}
\mathrm{TOP} & =\mathrm{U} \times \mathrm{OP} \\
& =23.475 \times 5=117.375
\end{aligned}
$$

d) Defect Per Opportunity (DPO)

Peluang terjadinya cacat produk bagi kualitas (CTQ)

$$
\mathrm{DPO}=\frac{\mathrm{D}}{\text { TOP }}=\frac{225}{117.375}=0,001917
$$

e) Defect Per Million Opportunities (DPMO)

Peluang yang terjadinya cacat produk terhadap karateristik bagi kualitas (CTQ) dalam 1 juta kesempatan.

$$
\begin{aligned}
& \text { DPMO = DPO } \times 1.000 .000 \\
& =0,001917 \times 1.000 .000=1916,933
\end{aligned}
$$

f). Penentuan level sigma

$$
\begin{aligned}
& =\text { normsinv }((1000000-\mathrm{DPMO}) / 1000000) \\
& +1,5 \\
& =4,391517
\end{aligned}
$$

\section{Tahap Analyze}

Tahap analisis untuk menganalisis tahap operasional dalam peningkatan kualitas six sigma. Alat yang digunakan pada tahap ini yaitu pembuatan diagram fishbone sebagai berikut :

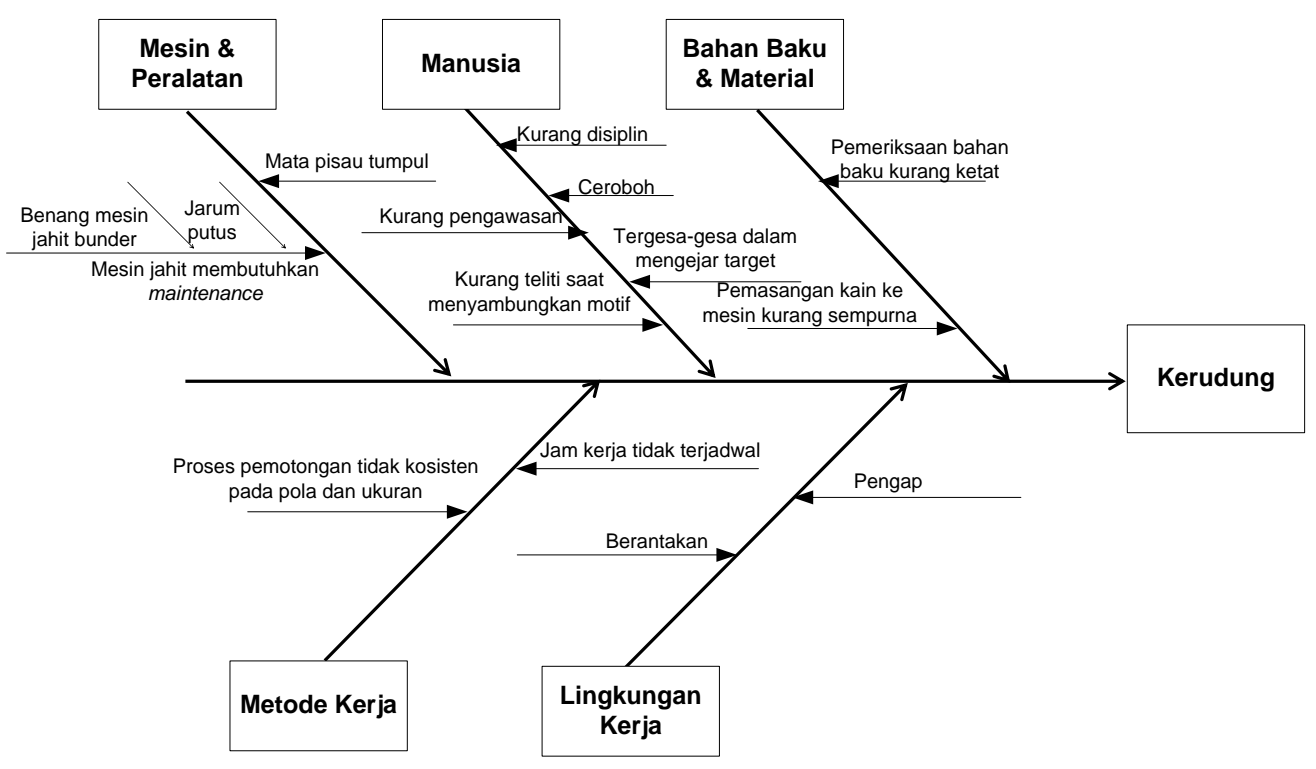

Gambar 10. Diagram Fishbone 
Mencari faktor penyebab dari proses pembuatan kerudung. Faktor - faktor yang mempengaruhi meliputi mesin peralatan

\section{Tahap Improve}

Tahap ini bertujuan untuk memberikan solusi terbaik dalam memecahkan masalah berdasarkan rencana-rencana tindakan yang dilakukan implementasi. Perbaikan dilakukan terhadap semua rencana tindakan yang digunakan, manusia, bahan baku material, lingkungan kerja dan metode kerja.

\begin{tabular}{|c|c|c|}
\hline Unsur & $\begin{array}{c}\text { Faktor } \\
\text { Penyebab }\end{array}$ & Usulan Tindakan \\
\hline Manusia & $\begin{array}{l}\text { 1.Tidak Teliti } \\
\text { dalam membuat } \\
\text { pola garis } \\
\text { pembuatan } \\
\text { kerudung } \\
\text { 2.Kurang Fokus } \\
\text { dalam } \\
\text { mengejar } \\
\text { target. } \\
\text { 3.Kurang teliti } \\
\text { saat } \\
\text { menyambungk } \\
\text { an warna motif } \\
\text { kerudung } \\
\text { 4.Pekerja } \\
\text { Ceroboh, } \\
\text { Kurang } \\
\text { Displin waktu } \\
\text { 5.Kurang } \\
\text { sadarnya } \\
\text { kualitas bahan }\end{array}$ & $\begin{array}{l}\text { 1. Perlu adanya } \\
\text { tindakan untuk } \\
\text { mengawasi saat } \\
\text { karyawan } \\
\text { bekerja. } \\
\text { 2. Perlu adanya } \\
\text { pelatihan } \\
\text { menjahit bagi } \\
\text { pegawai dengan } \\
\text { memberikan } \\
\text { training beberapa } \\
\text { hari } \\
\text { 3. Memberikan } \\
\text { arahan pada } \\
\text { karyawan tentang } \\
\text { disiplin waktu } \\
\text { saat bekerja. }\end{array}$ \\
\hline Material & $\begin{array}{l}\text { 1.Bahan baku } \\
\text { kain tidak } \\
\text { sesuai dengan } \\
\text { pemesanan, } \\
\text { seperti warna } \\
\text { tidak sesuai, } \\
\text { corak kain, } \\
\text { jenis kain } \\
\text { 2.Penyatuan saat } \\
\text { menjahit kain ke } \\
\text { mesin jahit } \\
\text { kurang } \\
\text { sempurna }\end{array}$ & $\begin{array}{l}\text { 1. Harus } \\
\text { memastikan } \\
\text { untuk bahan } \\
\text { baku pembuatan } \\
\text { kerudung sesuai } \\
\text { yang dipesan } \\
\text { dengan } \\
\text { spesifikasi yang } \\
\text { ditentukan. } \\
\text { 2. Sebelum } \\
\text { menggunakan } \\
\text { atau menjahit } \\
\text { kain cek awal } \\
\text { bahan baku yang } \\
\text { digunakan }\end{array}$ \\
\hline Mesin & $\begin{array}{l}\text { 1. Mahalnya biaya } \\
\text { pembelian } \\
\text { mesin jahit } \\
\text { dengan } \\
\text { teknologi yang } \\
\text { baru } \\
\text { 2.Penggunaan }\end{array}$ & $\begin{array}{l}\text { 1. Pastikan mesin } \\
\text { jahit yang } \\
\text { digunakan dalam } \\
\text { proses produksi } \\
\text { aman, stabil } \\
\text { untuk digunakan } \\
\text { 2. Selalu }\end{array}$ \\
\hline
\end{tabular}

perbaikan terhadap peningkatan kualitas produk yang dihasilkan atau rekomendasi usulan tindakan perbaikan secara umum. Usulan tindakan perbaikan dapat ditunjukkan pada Tabel 2. dibawah ini :

\section{Tabel 2. Usulan Tindakan Perbaikan}

\begin{tabular}{|c|c|c|}
\hline & $\begin{array}{l}\text { mesin jahit } \\
\text { pada benang } \\
\text { sering patah, } \\
\text { jarum putus, } \\
\text { mata pisau } \\
\text { tumpul } \\
\text { 3.Setting mesin } \\
\text { jahit kurang } \\
\text { tepat }\end{array}$ & $\begin{array}{l}\text { pengecekan } \\
\text { secara berkala, } \\
\text { membersihkan } \\
\text { mesin jahit, } \\
\text { memberikan } \\
\text { tambahan } \\
\text { pelumas (minyak) } \\
\text { dan perbaikan } \\
\text { terhadap } \\
\text { komponen mesin } \\
\text { yang lainnya. }\end{array}$ \\
\hline Metode & $\begin{array}{l}\text { 1.Proses } \\
\text { pemotongan } \\
\text { tidak konsinten } \\
\text { pada ukuran } \\
\text { pola yang } \\
\text { sudah } \\
\text { ditetapkan dan } \\
\text { harus diikuti } \\
\text { sesuai } \\
\text { modifikasi }\end{array}$ & $\begin{array}{l}\text { 1. Melakukan } \\
\text { produksi secara } \\
\text { continuous agar } \\
\text { jumlah yang } \\
\text { dihasilkan } \\
\text { produk sesuai } \\
\text { dengan } \\
\text { permintaan } \\
\text { konsumen } \\
\text { berdasarkan } \\
\text { trend. }\end{array}$ \\
\hline $\begin{array}{l}\text { Lingku } \\
\text { ngan }\end{array}$ & $\begin{array}{l}\text { 1.Cahaya } \\
\text { diruangan } \\
\text { kurang terbuka } \\
\text { 2.Lingkungan } \\
\text { kerja yang } \\
\text { kurang } \\
\text { kondusif } \\
\text { seperti suara } \\
\text { yang bising, } \\
\text { cahaya redup. }\end{array}$ & $\begin{array}{l}\text { 1. Menambahkan } \\
\text { ventilasi atau } \\
\text { pemberian } \\
\text { cahaya lampu } \\
\text { agar pegawai bisa } \\
\text { focus saat } \\
\text { bekerja. } \\
\text { 2. Memperluas } \\
\text { ukuran ruangan } \\
\text { pekerja, semakin } \\
\text { banyak } \\
\text { tumpukan kain } \\
\text { yang berserakan } \\
\text { dapat menganggu } \\
\text { pekerja tidak } \\
\text { nyaman. }\end{array}$ \\
\hline
\end{tabular}




\section{Tahap Control}

Tahap control ini merupakan tahap akhir dari proses six sigma. Yang merupakan upaya perbaikan dan evaluasi semua tindakan yang telah dilakukan untuk mengetahu seberapa keberhasilan atas upaya yang sudah diterapkan. Diagram SIPOC salah satu elemen utama didalam system pengendalian kualitas. Terdiri dari Supplier, Input, Process Output dan Customer. untuk mengidentifikasi proses pada peningkatan kualitas maka tahap identifikasi setiap proses yang dilakukan dapat diuraikan sebagai berikut :

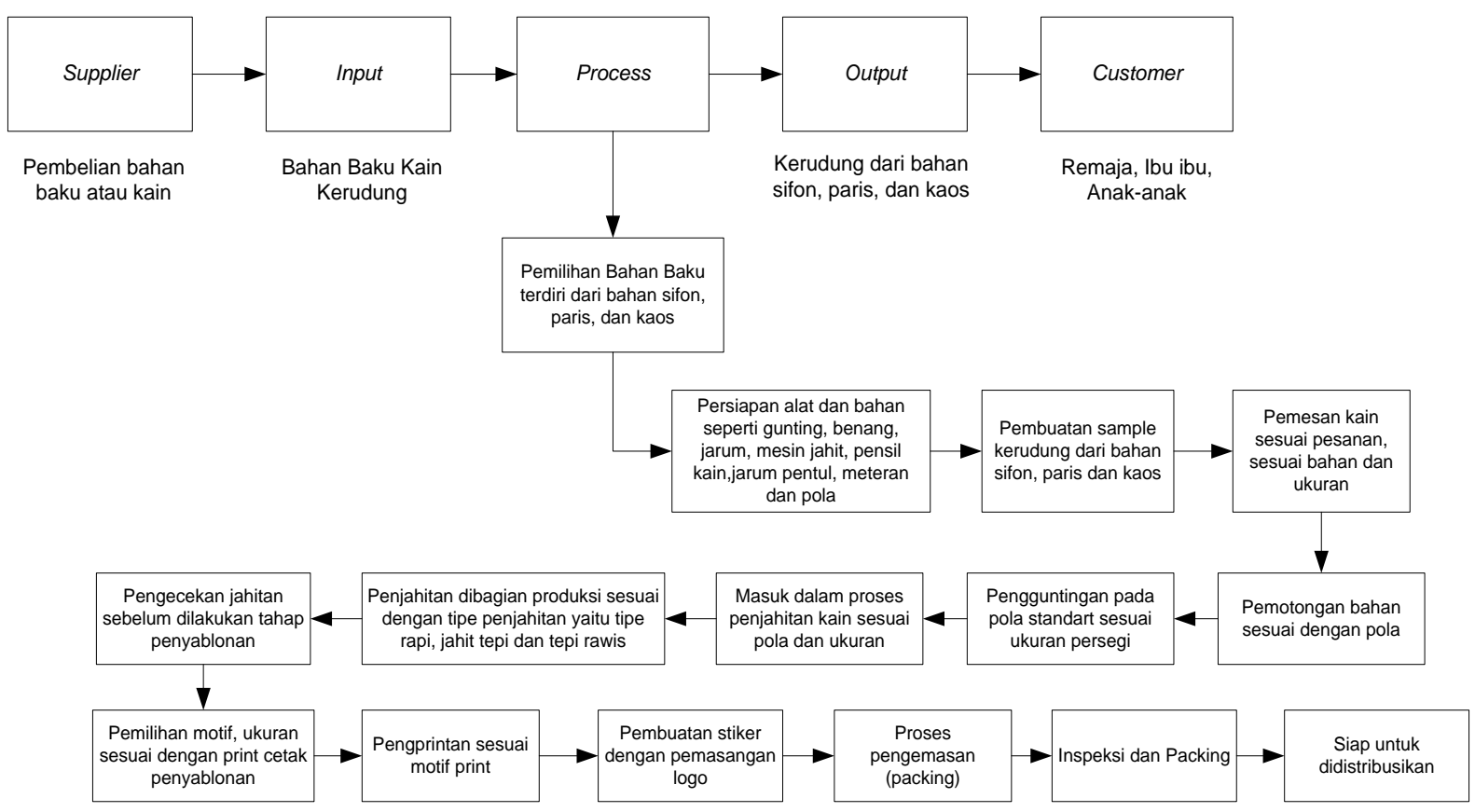

\section{Gambar 11. Diagram SIPOC}

\section{KESIMPULAN}

Berdasarkan hasil pengolahan data dan analisis yang telah dilakukan maka dapat ditarik kesimpulan sebagai berikut:

a. Hasil dari peramalan menggunakan metode exponential smoobing didapatkan nilai error MAD sebesar 17,97, MAPE sebesar 0,03 dan MSE sebesar 546,88.

b. Penyebab terjadinya cacat pada pembuatan kerudung pada bome industry kelelahan dan kurangnya konsentrasi pekerja saat melakukan pekerjaan, kurang pengawasan, kurang teliti, tergesa-tergesa dalam mengejar target produksi sehingga produk yang dihasilkan kurang memuaskan.

c. Usulan tindakan perbaikan yang harus dilakukan adalah dengan perbaikan dengan menetapkan standart metode yang dapat diimplementasikan pada proses produksi kerudung, selain itu pengawasan terhadap karyawan pekerja saat bekerja. 


\section{PENGHARGAAN}

1. Ucapan terimakasih disampaikan kepada DRPM Ristekdikti yang sudah mensupport pendanaan dalam penelitian ini, sehingga penelitian ini bisa selesai sesuai dengan yang diharapkan.

2. Lembaga Penelitian dan Pengabdian Masyarakat Sekolah Tinggi Teknik Qomaruddin Gresik

\section{DAFTAR PUSTAKA}

[1] Muhaemin, Achmad, 2012, Analisis Pengendalian Kualitas Produk dengan Metode Six Sigma pada Harian Tribun Timur. Skripsi. Fakultas Ekonomi dan Bisnis, Manajemen, Universitas Hasanuddin. Makassar, termuat di: bttp:// repository.unhas.ac.id/ handle/123456 7 89/1198 (Diakses pada 7 November 2019).

[2] Arminas dan Karanga, F.T. (2016). "Analisis Peramalan Penjualan Comforta' Bed Jenis Super Star Pada PT. Massindo Terang Perkasa Makassar," Seminar Nasional Sains dan Teknologi, Fakultas Teknik Universitas Muhammadiyah Jakarta.

[3] Gusdian, E., Abdul, M., dan Arifuddin. 2016. Peramalan Permintaan Produk Roti Pada Industri Tiara Rizki di Kelurahan Boyaoge Kecamatan Tatang Kota Palu. 4 (1):97-105.

[4] Gaspersz, Vincent. 2005. Pedoman Implementasi Program Six Sigma Terintegrasi dengan ISO 9001:2000,
MBNQA, dan HACCP. Jakarta: Gramedia Pustaka Utama.

[5] Assauri, Sofyan. 1984. Teknik dan Metode Peramalan. Penerbit Fakultas Ekonomi Universitas Indonesia: Jakarta.

[6] V. Mandasari and B. A. Tama, "Analisis Kepuasan Konsumen Terhadap Restoran Cepat Saji Melalui Pendekatan Data Mining: Studi Kasus XYZ," J. Generik, 2011.

[7] Ilham N.M. 2012. Analisis pengendalian kualitas produk dengan menggunakan Statistical Processing Control (SPC) pada PT. Bosowa Media Grafika (Tribun Timur). Skripsi. (Online). Makasar: Universitas Hasanuddin Makasar. http://core.ac.uk/download/pdf/25487 0 63.pdf. Diunduh pada 12 November 2019 pukul 21:00.

[8] Fithri dan Chairunnisa, (2019). "Six Sigma Sebagai Alat Pengendalian Mutu Pada Hasil Produksi Ikan Mentah PT. Unitex, Tbk. Jurnal Teknik Industri, 14. $1: 43-52$

[9] I. Ferreira, J. Cabral, and P. Saraiva, "An integrated framework based on the ECSI approach to link mould customers' satisfaction and product design," Total Qual. Manag. Bus. Excell., 2010.

[10] Nasapi M, dkk. 2014. Peramalan Permintaan Susu Pasteurisasi Menggunakan Metode Jaringan Syaraf Tiruan dan Time Series (Studi Kasus di Koperasi Susu SAE Pujon, Malang). Jurnal EECCIS Vol.6 (1), Hal : 1-12.

[11] Ginting, Rosnani. (2007). Sistem Produksi. Graha Ilmu: Yogyakarta. 